\title{
Effects of fortified milk on morbidity in young children in north India: community based, randomised, double masked placebo controlled trial
}

\author{
Sunil Sazawal, Usha Dhingra, Girish Hiremath, Jitendra Kumar, Pratibha Dhingra, Archana Sarkar, Venugopal P
}

Menon, Robert E Black

\begin{abstract}
Objective To evaluate the efficacy of milk fortified with specific multiple micronutrients on morbidity in children compared with the same milk without fortification.

Design Community based, double masked, individually randomised trial.

Setting Peri-urban settlement in north India.

Participants Children $(n=633)$ aged 1-3 randomly allocated to receive fortified milk $(n=316)$ or control milk $(n=317)$.

Intervention One year of fortified milk providing additional $7.8 \mathrm{mg}$ zinc, $9.6 \mathrm{mg}$ iron, $4.2 \mu \mathrm{g}$ selenium, $0.27 \mathrm{mg}$ copper, 156 $\mu \mathrm{g}$ vitamin A, $40.2 \mathrm{mg}$ vitamin C, 7.5 mg vitamin E per day (three feeds).

Main outcome measures Days with severe illnesses, incidence and prevalence of diarrhoea, and acute lower respiratory illness. Results Study groups were comparable at baseline; compliance in the groups was similar. Mean number of episodes of diarrhoea per child was 4.46 (SD 3.8) in the intervention (fortified milk) group and 5.36 (SD 4.1) in the control group. Mean number of episodes of acute lower respiratory illness was 0.62 (SD 1.1) and 0.83 (SD 1.4), respectively. The fortified milk reduced the odds for days with severe illnesses by $15 \%$ (95\% confidence interval $5 \%$ to $24 \%$ ), the incidence of diarrhoea by $18 \%(7 \%$ to $27 \%)$, and the incidence of acute lower respiratory illness by $26 \%$ (3\% to $43 \%$ ). Consistently greater beneficial effects were observed in children aged $\leq 24$ months than in older children.

Conclusion Milk is well accepted as a means of delivery of micronutrients. Consumption of milk fortified with specific micronutrients can significantly reduce the burden of common morbidities among preschool children, especially in the first two years of life.

Trial registration NCT00255385.
\end{abstract}

\section{Introduction}

The widespread prevalence of deficiencies in multiple micronutrients among preschool children is an important determinant of child health. ${ }^{2}$ Because they affect the immune system and have antioxidant properties some micronutrients have a crucial role in generation, maintenance, and amplification of immune response. $^{34}$ Animal models have shown that deficiency in specific micronutrients facilitates mutations in infectious agents, enhancing their infectivity and virulence. ${ }^{5}{ }^{6}$ Infectious diseases can also lead to deficiency of micronutrients, creating a vicious cycle between deficiency and morbidity and mortality from infections. ${ }^{7}$

Reducing the associated higher risk of infectious disease by alleviating deficiencies in micronutrients among young children in developing countries is now important in research and implementation in public health. The World Health Organization and the International Nutritional Anemia Consultative Group have recommended iron supplementation in preschool children. ${ }^{8}$ Clinical trials have shown that supplementation with zinc has a promising effect. ${ }^{9}$ Because of the inherent technical and practical limitations of a supplementation strategy, ${ }^{9-11}$ the limited success of nutritional education programmes, ${ }^{12}$ and the difficulty in promoting animal based foods, ${ }^{13}$ delivery of zinc and iron through fortification of commonly consumed foods remains the only practical and sustainable option. National fortification programmes and fortification studies have shown that fortification of common home based food can overcome the limitations inherent to supplementation at a lower cost. ${ }^{14-16}$ Milk is a popular food for fortification because it is readily available, widely accepted, and frequently fed to young children.

To evaluate acceptability and efficacy of delivering specific micronutrients, including zinc and iron, through fortified milk we conducted a community based, double masked, randomised controlled trial comparing fortified milk with the same milk without fortification for prevention of common childhood morbidities.

\section{Methods}

\section{Participants}

The trial was carried out in Sangam Vihar, a peri-urban population in New Delhi, India, from April 2002 to April 2004. Details of the population have been previously published. ${ }^{17}{ }^{18}$ From a regularly updated demographic database we invited all permanently resident families with children aged 1-3 years to participate in the study and sought their consent. Irrespective of group allocation all children who had severe anaemia at baseline were given a therapeutic dose of iron for three months in addition to their milk supplement.

\section{Baseline assessment, blood samples, and laboratory procedures}

After we obtained consent, children were enrolled and scheduled to visit the clinic. A detailed baseline assessment included examination by a physician and the collection of socioeconomic and demographic information. Two independent observers meas- 
ured weight to the nearest $10 \mathrm{~g}$ with an electronic scale (SECA Corporation, Columbia, MD) and length or height to the nearest $0.1 \mathrm{~cm}$ with length boards (Shorr Productions, Olney, MD). Researchers collected a venous blood sample at baseline and at the end of the study in trace element-free syringes. The blood was transferred into vials with EDTA, and vials with zinc-free heparin. Plasma was separated within 15 minutes of blood collection and aliquots transferred into trace element-free Eppendorf plastic tubes for storage at $-20^{\circ} \mathrm{C}$. The EDTA blood was analysed on the same day with a Coulter automated haematology analyser for a detailed haemogram. One drop of blood was used to estimate zinc protoporphyrin with a fluorometer (Aviv Biomedical, Lakewood, NJ). Plasma concentration of zinc was estimated with standard methods with an atomic absorption spectrometer (AAS 800-Perkin Elmer). ${ }^{19}$ Serum ferritin and serum transferrin concentrations were estimated in plasma samples with a commercial enzyme linked immunoabsorbent assay (ELISA; Ramco Laboratories, Houston, TX).

\section{Randomisation and masking}

This study was implemented concurrently with another two-armed clinical trial to evaluate the efficacy of a different milk preparation fortified with probiotic (compared with that preparation without fortification) in a non-factorial design with joint randomisation. Each treatment group (across the two trials) was identified by a letter code A, B, C, or D. A random allocation sequence of group codes was generated with our own software, with permuted blocks of length 16 .

We generated two separate randomisation lists-one for children with baseline $\mathrm{Hb}>70 \mathrm{~g} / \mathrm{l}$ and another for children with baseline $\mathrm{Hb} \leq 70 \mathrm{~g} / \mathrm{l}$. This resulted in two serially numbered lists with allocated treatment codes before we enrolled any children. When we entered the baseline information for each child (including haemoglobin concentration), the child was automatically allocated the next available serial number and the letter code in the haemoglobin group. The supplementation sachets were identical in colour, size (weight $32 \mathrm{~g}$ ), and taste and were labelled with a letter code. The product corresponding with the letter code was known only to the manufacturing supervisor in New Zealand; it was not known to investigators or anyone in the field until the study was finished and the data analysed. In the field, the letter code of the supplementation box was stripped off and labelled with the child's identification information. We report here on children allocated to two of the four letter codes.

\section{Sample size and power}

We calculated the sample size using actual data from one of our recently concluded studies. We used a rate of 0.019 (6.8 episodes/child year) for diarrhoea and 0.003 (1.05 episodes/ child) for pneumonia. Assuming a Poisson distribution for incidence, we aimed at a $15 \%$ reduction in diarrhoea and 25\% reduction in pneumonia, at an $\alpha$ of 0.05 and $90 \%$ power. We inflated the estimated sample size by $10 \%$ to account for possible clustering of events and by another $10 \%$ to account for potential attrition of children participating in the trial and therefore enrolled 325 children in each group.

\section{Intervention}

We used $32 \mathrm{~g}$ single serving sachets of fortified milk powder (Fonterra Brands, New Zealand). At enrolment, mothers were shown how to reconstitute the powdered milk. Table 1 shows the composition of milk in the two groups. Assistants delivered 21 sachets each week to each home and advised that the child should consume up to three sachets a day. Supplementation was continued for one year. We recorded the use of additional
Table 1 Composition of milk preparation as nutritive value in three serving

\begin{tabular}{|c|c|c|}
\hline & Fortified milk & Control milk \\
\hline Energy (MJ) & 1.89 & 1.89 \\
\hline Protein $(\mathrm{g})$ & 20.1 & 20.1 \\
\hline Taurine (mg) & 48 & 48 \\
\hline Carbohydrate $(\mathrm{g})$ & 48.9 & 48.9 \\
\hline Fat $(\mathrm{g})$ & 18.9 & 18.9 \\
\hline Vitamin $A^{*}(\mu \mathrm{g})$ & 330 & 174 \\
\hline Vitamin $D_{3}(\mu \mathrm{g})$ & 3.6 & 3.6 \\
\hline Vitamin E† (mg) & 8.1 & 0.6 \\
\hline Vitamin C (mg) & 48.0 & 7.8 \\
\hline Thiamin (mg) & 0.6 & 0.6 \\
\hline Riboflavin (mg) & 1.8 & 1.8 \\
\hline Niacin (mg) & 4.5 & 4.5 \\
\hline Vitamin $B_{6}(\mathrm{mg})$ & 0.6 & 0.6 \\
\hline Pantothenic acid (mg) & 2.7 & 2.7 \\
\hline Folate $\neq(\mu \mathrm{g})$ & 114 & 114 \\
\hline Vitamin $B_{12}(\mu \mathrm{g})$ & 2.7 & 2.7 \\
\hline Biotin $(\mu \mathrm{g})$ & 24.9 & 24.9 \\
\hline Choline (mg) & 114 & 114 \\
\hline Calcium (mg) & 720 & 720 \\
\hline Phosphorus (mg) & 600 & 600 \\
\hline Magnesium (mg) & 84 & 84 \\
\hline Iron (mg) & 9.6 & 0 \\
\hline Zinc (mg) & 9.6 & 1.8 \\
\hline Iodine $(\mu \mathrm{g})$ & 36 & 36 \\
\hline Selenium $(\mu \mathrm{g})$ & 6.6 & 2.4 \\
\hline Copper (mg) & 0.3 & 0.03 \\
\hline Sodium (mg) & 360 & 360 \\
\hline Potassium (mg) & 1260 & 1260 \\
\hline Chloride (mg) & 900 & 900 \\
\hline
\end{tabular}

${ }^{*}$ Retinol activity equivalents.

$\dagger \alpha$ tocopherol equivalents.

‡Dietary folate equivalents.

sachets given at the parents' request to children going away from home. To prevent sharing of supplement with other siblings, mothers could be given more sachets. The intervention (fortified milk in three servings a day) was designed to deliver zinc $9.6 \mathrm{mg}$ (7.8 mg more than control group) and iron $9.6 \mathrm{mg}$. The fortified milk also included extra vitamin $\mathrm{C}$ to improve iron absorption, copper to counteract possible effects of zinc and iron on copper absorption, selenium, vitamin $\mathrm{A}$, and vitamin $\mathrm{E}$ to help antioxidant and immune effects of zinc.

\section{Household surveillance during follow-up}

During weekly visits to households assistants distributed the milk sachets and collected unconsumed sachets and information on compliance. Other assistants visited homes twice a week to collect morbidity information since the last visit. Both teams gathered information on compliance and were retrained for two to three months on the specific instruments used. If the child or the parent was not available on a scheduled visit day, the team revisited the household the next day. There were two levels of supervision and random checking. About $10 \%$ of the houses were randomly visited to verify the overall information gathered. At each home visit, supervisors recorded information for each of the previous three to four days since the last visit, including number of diarrhoeal stools, consistency of stools, blood in stools, pneumonia, fever, vomiting, and history of feeding. They also cross checked compliance with consumption of milk. Mothers were advised to contact study physicians at the clinic if they thought that the child was seriously ill between visits. All visits either to the study physicians or to private physicians were recorded. Treatment of diarrhoea, dysentery and pneumonia as 
per WHO guidelines was provided free to the participating children throughout the study.

\section{Primary outcomes and definition of clinical outcomes}

Our primary outcomes were episodes of diarrhoea and acute lower respiratory tract infections or pneumonia and days with severe illness. Diarrhoea was defined as three or more loose or watery stools in 24 hours, and children were considered to have recovered after three days without diarrhoea. Acute lower respiratory tract infection was diagnosed if the child had reported difficulty in breathing and rapid breathing $(\geq 40 / \mathrm{min})$. Severe illness consisted of temperature $\geq 38.4^{\circ} \mathrm{C}$ or admission to hospital or respiratory rate $\geq 50 / \mathrm{min}$ or chest indrawing. Dysentery was defined as diarrhoea with visible blood in stools, severe acute lower respiratory tract infections (worsening of existing infection or new onset of cough or difficulty in breathing with high respiration rate $(\geq 50 / \mathrm{min})$ or chest indrawing), fever (axillary temperature $\geq 37.2^{\circ} \mathrm{C}$ ), and high fever (axillary temperature $\geq 38.4^{\circ} \mathrm{C}$ ).

\section{Data management and statistical methods}

We used Visual Basic 6.0 and Oracle 8 i to manage our data, with stringent range, consistency, and logical checks. Real time data entry ensured data quality and accuracy. We used double data entry and manual checking of frequencies during data cleaning before the code was broken. For primary analysis we used alphabetical codes for groups still blinded to real group identity. We performed intent to treat analysis (all children were included in analyses irrespective of their adherence to the supplement) and included all data gathered during the intervention period of one year. For children leaving the study area or withdrawing from the study, we included data until the date of censorship. Person-time analysis was performed with actual follow-up as denominator. For the effect on incidence of diarrhoea, acute lower respiratory tract infection, and measles, we estimated relative risk using Poisson regression; and for prevalence, we estimated odds ratio using GLM for binomial outcomes (maximum likelihood logit estimation for grouped data). In both estimations, we used robust clustered standard error estimation, the clustering variable being the child..$^{20}{ }^{21}$ This modified sandwich estimator is unbiased for cluster correlated data regardless of the setting. All statistical analyses were performed in STATA 9.2, (StataCorp, College Station, TX).

\section{Results}

Out of 660 eligible children contacted, we received consent for 633 children (316 in intervention, 317 in control) to participate in the study (figure) and collected data on 190324 child days of follow-up. The children in both the groups were comparable at baseline for sociodemographic variables, haematology, and plasma zinc status (table 2). The mean number of sachets consumed was 2.58 in the intervention group and 2.54 in the control group. On $77.4 \%$ and $77.3 \%$ child days, respectively, an intake of three sachets was recorded. Only $30(9.5 \%)$ children in the intervention group and $19(6.0 \%)$ in the control group did not have any episodes of diarrhoea. The mean number of episodes of diarrhoea per child per year was 4.46 (SD 3.8) and 5.36 (SD 4.1), respectively, the figures for acute lower respiratory tract infection being 0.62 (SD 1.1) and 0.83 (SD 1.4). Compared with non-fortified milk, consumption of fortified milk was associated with an $18 \%$ (95\% confidence interval $7 \%$ to $27 \%)$ lower incidence of diarrhoea and a similarly lower prevalence of diarrhoea. The difference was significant, irrespective of age. The subgroup analyses were performed more as explanatory analyses ( $\leq 24$ months $v>24$ months). The incidence of acute

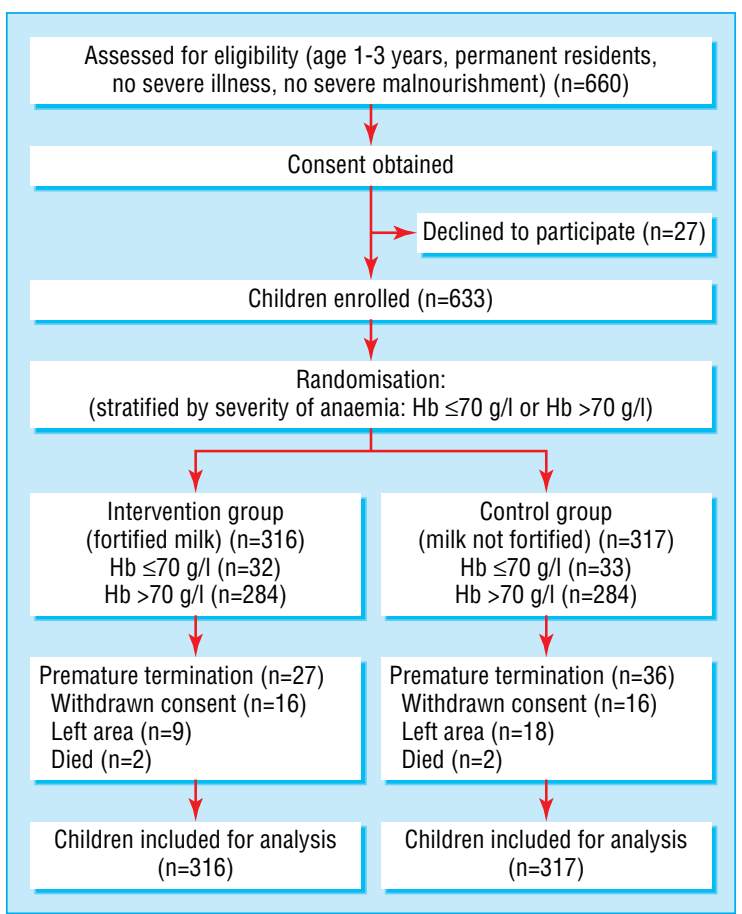

Flow of the participants through study

lower respiratory tract infection was $26 \%$ (3\% to $43 \%$ ) lower in the intervention group than in the control group. In children $\leq 24$ months of age, the incidence was $47 \%$ (19\% to $65 \%)$ lower. There was a significant reduction in prevalence of days with high respiratory rate ( $\geq 40 / \mathrm{min})$. Overall days with severe illness were $15 \%$ (5\% to $24 \%)$ lower in the intervention group than in the control group. Although there was $88 \%$ (1\% to $98 \%)$ reduction in risk for measles in the intervention group, there were few episodes $(1 v 8)$. There was $4 \%(1 \%$ to $8 \%)$ lower use of antibiotics in the intervention group compared with the control group. Table 3 summarises the results. Adherence to the milk feeds was similar in the groups; $85.6 \%$ in the intervention group and $86.7 \%$ in the control group consumed two or three servings on more than $80 \%$ of days. This did not vary by the intervention period, and there were no adverse events observed.

\section{Discussion}

In this study children who received fortified milk compared with those who received same quantity and quality milk without specific fortification had 18\% lower incidence of diarrhoea, 26\% lower incidence of pneumonia, $7 \%$ fewer days with high fever, and 15\% fewer days sick with severe illnesses. The significantly lower rates of measles and use of antibiotics suggest that fortification resulted in a substantial prevention of morbidity. Together these effects suggest improved immunity against common infections. The fact that all children in the study received about 1.89 MJ energy, $20 \mathrm{~g}$ protein, $49 \mathrm{~g}$ carbohydrates, and $19 \mathrm{~g}$ fat, in addition to their complementary foods or breast milk, suggests that these effects could be expected even in moderately well fed children.

Our study was in keeping with the recently ratified WHO global strategy on infant and young child feeding, which notes that industrially processed complementary foods are an option for mothers who can afford them and have the knowledge and facilities to safely prepare and feed them. ${ }^{22}$ We used fortified milk to deliver zinc and iron. Addition of copper to foods fortified with zinc and iron is recommended because of potential negative 
Table 2 Baseline sociodemographic characteristics of two groups according to allocation to fortified (intervention) or non-fortified (control) milk. Figures are numbers (percentages) of participants unless stated otherwise

\begin{tabular}{|c|c|c|}
\hline & $\begin{array}{l}\text { Intervention } \\
\quad(n=316)\end{array}$ & Control $(n=317)$ \\
\hline \multicolumn{3}{|l|}{ Age (months): } \\
\hline Mean (SD) & $22.4(6.8)$ & $23.0(6.7)$ \\
\hline$\leq 24$ & $191(60)$ & $187(59)$ \\
\hline$>24$ & $125(40)$ & $128(41)$ \\
\hline Boys & $154(49)$ & $163(51)$ \\
\hline Illiterate father & $54(17)$ & $52(16)$ \\
\hline Illiterate mother & $168(53)$ & $169(53)$ \\
\hline Mean (SD) SES* score & $7.14(2.7)$ & $7.28(2.5)$ \\
\hline Water supply from tap & $183(58)$ & $187(59)$ \\
\hline \multicolumn{3}{|l|}{ Haemoglobin $(\mathrm{g} / \mathrm{l})$ : } \\
\hline Mean (SD) & $89.2(15.0)$ & $91.0(15.0)$ \\
\hline$\leq 70 \dagger$ & $32(10)$ & $33(10)$ \\
\hline$>70 \dagger$ & $284(90)$ & $284(90)$ \\
\hline Mean (SD) serum transferrin $(\mu \mathrm{g} / \mathrm{ml})$ & $25.8(11.3)$ & $26.9(11.0)$ \\
\hline Mean (SD) serum ferritin $(\mu \mathrm{g} / \mathrm{l})$ & $9.6(12.9)$ & $9.9(9.4)$ \\
\hline Mean (SD) plasma zinc $(\mu \mathrm{mol} / \mathrm{l})$ & $9.3(3.6)$ & $9.6(4.1)$ \\
\hline \multicolumn{3}{|l|}{ Nutritional status: } \\
\hline Wasted and stunted & $62(21)$ & $69(23)$ \\
\hline Normal & $113(38)$ & $112(37)$ \\
\hline Stunted & $68(23)$ & $65(21)$ \\
\hline Wasted & $55(18)$ & $57(19)$ \\
\hline
\end{tabular}

*Socioeconomic status based on ownership and type of house and household items; maximum=26; higher scores=higher status.

effects of zinc and iron supplementation on copper absorption and status. ${ }^{23}$ We added vitamin A, selenium, and vitamin $\mathrm{E}$ to the supplement because they might improve the immune and membrane stabilising effects and vitamin $\mathrm{C}$ to improve iron absorption. These were added to recommended levels for fortified complementary foods. Though this strategy might optimise the effect of the intervention, it limits our ability to determine the contributions of individual micronutrients.

Table 3 Effect on morbidity according to allocation to fortified (intervention) or non-fortified (control) milk (robust estimates)

\begin{tabular}{|c|c|c|c|c|}
\hline & $\begin{array}{l}\text { Intervention } \\
(\mathrm{n}=316)\end{array}$ & $\begin{array}{l}\text { Control } \\
(\mathrm{n}=317)\end{array}$ & $\begin{array}{c}\text { Relative risk or } \\
\text { odds ratio }(95 \% \mathrm{Cl})\end{array}$ & $\begin{array}{c}P \\
\text { value }\end{array}$ \\
\hline \multicolumn{5}{|l|}{ Gastrointestinal morbidity } \\
\hline \multicolumn{5}{|l|}{ Episodes of diarrhoea: } \\
\hline All children (aged 1-3 years) & 1408 & 1700 & 0.82 (0.73 to 0.93$)$ & 0.002 \\
\hline Age $\leq 24$ months & 529 & 555 & 0.84 (0.71 to 0.96) & 0.03 \\
\hline Age $>24$ months & 879 & 1145 & 0.80 (0.69 to 0.93$)$ & 0.004 \\
\hline Days of diarrhoea & 3277 & 4010 & $0.81^{*}(0.77$ to 0.85$)$ & 0.00 \\
\hline Episodes of dysentery & 121 & 133 & 0.91 (0.67 to 1.22) & 0.52 \\
\hline \multicolumn{5}{|l|}{ Respiratory morbidity } \\
\hline \multicolumn{5}{|c|}{ Episodes of acute lower respiratory illness: } \\
\hline All children (aged 1-3 years) & 195 & 262 & 0.74 (0.57 to 0.97$)$ & 0.03 \\
\hline Age $\leq 24$ months & 71 & 117 & 0.53 (0.35 to 0.81$)$ & 0.003 \\
\hline Age $>24$ months & 124 & 145 & 0.89 (0.67 to 1.19) & 0.42 \\
\hline $\begin{array}{l}\text { Days with respiration rate } \\
>40 / \mathrm{min} \\
\end{array}$ & 279 & 368 & $0.75^{\star} \quad(0.65$ to 0.88$)$ & 0.00 \\
\hline $\begin{array}{l}\text { Severe episodes of acute lower } \\
\text { respiratory illness }\end{array}$ & 79 & 110 & 0.72 (0.49 to 1.05$)$ & 0.09 \\
\hline \multicolumn{5}{|l|}{ Febrile illness and others } \\
\hline \multicolumn{5}{|l|}{ Days with severe illness: } \\
\hline All children (aged 1-3 years) & 530 & 621 & $0.85^{\star} \quad(0.76$ to 0.95$)$ & 0.006 \\
\hline Age $\leq 24$ months & 186 & 254 & $0.64^{*} \quad(0.53$ to 0.77$)$ & 0.00 \\
\hline Age $>24$ months & 344 & 367 & $0.97^{\star} \quad(0.84$ to 1.13$)$ & 0.73 \\
\hline Days with high fever & 2899 & 3099 & $0.93^{*}(0.88$ to 0.98$)$ & 0.005 \\
\hline Measles & 1 & 8 & 0.12 (0.02 to 0.99$)$ & 0.05 \\
\hline Antibiotics consumed (doses) & 7166 & 7437 & $0.96^{*} \quad(0.92$ to 0.99$)$ & 0.01 \\
\hline
\end{tabular}

There is a growing consensus that both zinc and iron should be given to vulnerable groups, including preschool children. ${ }^{24-26}$ The recent WHO/UNICEF review of complementary foods in developing countries concluded that iron and zinc requirements may be difficult to meet from non-fortified complementary foods. ${ }^{27}$ In view of their interaction shown in isotope studies, the mode of provision needs to be considered carefully. ${ }^{28}{ }^{29}$ Evidence from supplementation trials is inconclusive. ${ }^{30}$ Interaction does not seem to occur when two elements are presented in food products or in the presence of dietary ligands. ${ }^{31-33}$ Thus, it is likely that the preferred delivery of these two micronutrients will be as fortification rather than supplementation.

The effects on febrile illness, measles, diarrhoea, and acute lower respiratory infections are consistent with results of recently published clinical trials on the effect of routine zinc supplementation on incidence of diarrhoea ${ }^{3133-36}$ and acute lower respiratory tract infections. ${ }^{37}$ Given the design of this study we cannot estimate interaction between these minerals, but our results do suggest an overall benefit and thus a lack of any significant negative interaction between zinc and iron when provided in the fortified milk.

In recent years mechanisms for nutritional modulation of the immune response have been investigated and are now better understood. Lack of selected micronutrients-especially zinc, selenium, iron, and the antioxidant vitamins-can lead to clinically important immune deficiency and infections in children. These nutrients act as antioxidants and cofactors at the level of cytokine regulation and can affect cytokine response and immune cell trafficking. ${ }^{38}$

\section{Conclusion}

Given that the latest estimates of the percentage of gross domestic product lost to all forms of vitamin and mineral deficiency is $1-2 \%$ in the developing world, ${ }^{39}$ there is an urgent need to develop and implement strategies to reduce the burden of these deficiencies. We have shown that micronutrients, especially zinc and iron, at levels that have been traditionally delivered by supplementation, can be delivered successfully through fortified milk. This mode of delivery is well accepted and retains the prevention of morbidity shown in zinc supplementation trials while also being able to deliver iron and other specific micronutrients.

\section{What is already known on this topic}

Deficiency in specific micronutrients, especially iron and zinc, is prevalent in preschool children in developing countries and predisposes these children to common childhood infections

Supplementation with zinc leads to significant reduction in morbidity from diarrhoea or pneumonia

Supplementation is difficult to implement and has not been successful in prevention of iron deficiency

\section{What this study adds}

Fortified milk is well accepted as an intervention to deliver specific micronutrients with sustained compliance

Consumption of milk fortified with zinc, iron, and specific micronutrients is associated with decreased incidence of diarrhoea, acute lower respiratory tract infections, and days with severe illness 
We gratefully acknowledge the contributions of parents of children enrolled in the study and the study team, including health workers, supervisors, physicians, data management, and other support staff.

Contributors: SS was the principal investigator, designed the study, formulated the hypothesis, directed the study and the analyses, wrote the paper, and is guarantor. UD helped to design and develop data collection forms, designed the database management system, analysed data, and edited the paper. GH helped to interpret the results and write the paper.JK supervised the field procedures, implementation of the study, data collection, data entry, and quality control. PD and AS prepared the operation manual, were involved in design and translation of data collection forms and data collection, and prepared the manuscript. VPM helped in design, interpretation, and writing. REB contributed to design, interpretation, and writing.

Funding: Fonterra Brands, Auckland, New Zealand, funded the study and provided the milk powder used in the trial.

Competing interests: None declared.

Ethical approval: Human research and ethical review committee at the Johns Hopkins Bloomberg School of Public Health, and the Annamalai University, India.

1 Gross R, Benade S, Lopez G. The international research on infant supplementation initiative. J Nutr 2005; 135:628-30S.

2 Ramakrishnan U. Prevalence of micronutrient malnutrition worldwide. Nutr Rev 2002;60:S46-52.

3 Bhaskaram P. Micronutrient deficiencies in children-the problem and extent. Indian J Pediatr 1995;62:145-56.

4 Calder PC, Kew S. The immune system: a target for functional foods? Br J Nutr 2002;88(suppl 2):165-77.

5 Beck MA, Handy J, Levander OA. Host nutritional status: the neglected virulence factor. Trends Microbiol 2004;12:417-23.

6 Black RE, Sazawal S. Zinc and childhood infectious disease morbidity and mortality. $\mathrm{Br}$ J Nutr 2001;85(suppl 2):125-9.

7 Guerrant RL, Lima AA, Davidson F. Micronutrients and infection: interactions and implications with enteric and other infections and future priorities. $J$ Infect Dis 2000;182(suppl 1):134-8.

8 International Nutritional Anemia Consultative Group. Consensus statement. Safety of iron supplementation programs in malaria-endemic regions. Washington DC: International Life Sciences Institute Press, 1999

9 Bhutta ZA, Black RE, Brown KH, Gardner JM, Gore S, Hidayat A, et al. Prevention of diarrhea and pneumonia by zinc supplementation in children in developing countries: pooled analysis of randomized controlled trials. Zinc investigators' collaborative group. J Pediatr 1999;135:689-97.

10 Allen LH. Iron supplements: scientific issues concerning efficacy and implications for research and programs. J Nutr 2002;132(4 suppl):813-9.

11 World Health Organization. Iron deficiency anaemia: assessment, prevention, and control. Geneva, Switzerland: World Health Organization, 2001 (WHO/NID/01.3).

12 Bhandari N, Mazumder S, Bahl R, Martines J, Black RE, Bhan MK. An educational intervention to promote appropriate complementary feeding practices and physical growth in infants and young children in rural Haryana, India. J Nutr 2004;134:2342-8.

13 Rivera JA, Hotz C, Gonzalez-Cossio T, Neufeld L, Garcia-Guerra A. The effect of micronutrient deficiencies on child growth: a review of results from community-based supplementation trials. J Nutr 2003;133(suppl 2):4010-20.

14 Torrejon CS, Castillo-Duran C, Hertrampf ED, Ruz M. Zinc and iron nutrition in Chilean children fed fortified milk provided by the complementary national food program. Nutrition 2004:20:177-80.

15 Salgueiro MJ, Zubillaga M, Lysionek A, Caro R, Weill R, Boccio J. Fortification strategies to combat zinc and iron deficiency. Nutr Rev 2002;60:52-8.

16 Beinner MA, Lamounier JA. Recent experience with fortification of foods and beverages with iron for the control of iron-deficiency anemia in Brazilian children. Food Nutr Bull 2003;24:268-74.

17 Sazawal S, Black RE, Menon VP, Dhinghra P, Caulfield LE, Dhingra U, et al. Zinc supplementation in infants born small for gestational age reduces mortality: a prospective, randomized, controlled trial. Pediatrics 2001;108:1280-6.

18 Black MM, Sazawal S, Black RE, Khosla S, Kumar J, Menon V. Cognitive and motor development among small-for-gestational-age infants: impact of zinc supplementation, birth weight, and caregiving practices. Pediatrics 2004;113:1297-305.
19 Hambidge KM, King JC, Kern DL, English-Westcott JL, Stall C. Pre-breakfast plasma zinc concentrations: the effect of previous meals. J Trace Elem Electrolytes Health Dis 1990;4:229-231.

20 Williams RL. A note on robust variance estimation for cluster-correlated data. Biometrics 2000;56:645-6.

21 Rogers WH. Regression standard errors in clustered samples. Stata Tech Bull $1993 ; 13: 19-23$.

22 World Health Organization. Global strategy for infant and young child feeding. Geneva: World Health Organization, 2003 (WS 120).

23 Lutter CK, Dewey KG. Proposed nutrient composition for fortified complementary foods. J Nutr 2003;133:3011-20S.

24 Idjradinata P, Pollitt E. Reversal of developmental delays in iron-deficient anaemic infants treated with iron. Lancet 1993;341:1-4.

25 Fischer WC, Black RE. Zinc and the risk for infectious disease. Annu Rev Nutr 2004;24:255-75.

26 Brown KH, Peerson JM, Rivera J, Allen LH. Effect of supplemental zinc on the growth and serum zinc concentrations of prepubertal children: a meta-analysis of randomized controlled trials. Am J Clin Nutr 2002;75:1062-71.

27 World Health Organization. Complementary feeding of young children in developing countries: a review of current scientific knowledge. Geneva: WHO, 1998 (WHO/NUT/98.1). 28 Solomons NW, Jacob RA. Studies on the bioavailability of zinc in humans: effects of heme and nonheme iron on the absorption of zinc. Am J Clin Nutr 1981;34:475-82.

29 Rossander-Hulten L, Brune M, Sandstrom B, Lonnerdal B, Hallberg L. Competitive inhibition of iron absorption by manganese and zinc in humans. Am J Clin Nutr 1991;54:152-6.

30 Fischer WC, Kordas K, Stoltzfus RJ, Black RE. Interactive effects of iron and zinc on biochemical and functional outcomes in supplementation trials. Am I Clin Nutr 2005;82:5-12.

31 Solomons NW, Jacob RA, Pineda O, Viteri FE. Studies on the bioavailability of zinc in man. Effects of the Guatemalan rural diet and of the iron-fortifying agent, NaFeEDTA. J Nutr 1979;109:1519-28.

32 Sandstrom B, Davidsson L, Cederblad A, Lonnerdal B. Oral iron, dietary ligands and zinc absorption. J Nutr 1985;115:411-4.

33 Davidsson L, Kastenmayer P, Hurrell RF. Sodium iron EDTA [NaFe(III)EDTA] as a food fortificant: the effect on the absorption and retention of zinc and calcium in women. Am J Clin Nutr 1994;60:231-7.

34 Sazawal S, Black RE, Bhan MK, Jalla S, Sinha A, Bhandari N. Efficacy of zinc supplementation in reducing the incidence and prevalence of acute diarrhea-a community-based, double-blind, controlled trial. Am J Clin Nutr 1997;66:413-8.

35 Rosado JL, Lopez P, Munoz E, Martinez H, Allen LH. Zinc supplementation reduced morbidity, but neither zinc nor iron supplementation affected growth or body composition of Mexican preschoolers. Am J Clin Nutr 1997;65:13-9.

36 Penny ME, Marin RM, Duran A, Peerson JM, Lanata CF, Lonnerdal B, et al. Randomized controlled trial of the effect of daily supplementation with zinc or multiple micronutrients on the morbidity, growth, and micronutrient status of young Peruvian children. Am J Clin Nutr 2004;79:457-65.

37 Sazawal S, Black RE, Jalla S, Mazumdar S, Sinha A, Bhan MK. Zinc supplementation reduces the incidence of acute lower respiratory infections in infants and preschool children: a double-blind, controlled trial. Pediatrics 1998;102:1-5.

38 Cunningham-Rundles S, McNeeley DF, Moon A. Mechanisms of nutrient modulation of the immune response. J Allergy Clin Immunol 2005;115:1119-28.

39 Adamson P. Vitamins and mineral deficiency: a global progress report. Ottawa, Canada/New York: UNICEF, 2004.

(Accepted 3 November 2006)

doi $10.1136 /$ bmj.39035.482396.55

Johns Hopkins Bloomberg School of Public Health, Baltimore, MD 21205, USA

Sunil Sazawal associate professor

Usha Dhingra data analyst

Girish Hiremath postdoctoral fellow

Robert E Black professor

Center for Micronutrient Research, Department of Biochemistry, Annamalai

University, Chidambaram, India

Jitendra Kumar project manager

Pratibha Dhingra senior research scientist

Archana Sarkar senior research scientist

Venugopal P Menon professor

Correspondence to: S Sazawal ssazawal@jhsph.edu 